\title{
Vida sindical y sociabilidades masculinas: los trabajadores ferroviarios en la Argentina de principios del siglo $\mathrm{XX}^{1}$
}

\author{
Florencia D'Uva - Silvana A. Palermo \\ IIEGE-UBA, Conicet / UNGS, Conicet \\ florduva@yahoo.com.ar / palermosilvi@gmail.com
}

Durante la década de 1910, los ferroviarios dificilmente podian hacer caso omiso de la actividad gremial. Las malas cosechas y el inicio de la Gran Guerra condujeron a las empresas ferroviarias a la racionalización y forzaron a los ferroviarios a un súbito deterioro de sus condiciones de trabajo y de vida. En el campo político, sin embargo, la aprobación de la ley electoral, que imponía a todos los varones nativos y naturalizados el sufragio obligatorio y secreto, revitalizó la vida pública, las contiendas electorales y abrió nuevas posibilidades para poner en discusión la llamada cuestión social. En este contexto, los ferroviarios redoblaron sus esfuerzos organizativos y expresaron sus demandas con resultados disímiles. Organizados en una de las entidades gremiales pioneras de Argentina, a comienzos de 1912 los maquinistas y foguistas representados por La Fraternidad (LF), emprendieron una huelga de 52 días que concluyó en un duro fracaso. Por su parte, el personal de tráfico, talleres y vía y obra retomaba sus intentos de organización, tras una breve pero intensa experiencia de sindicalización entre 1903 y 1907, la Confraternidad Ferroviaria. En efecto, en 1912, nacia la Federación Obrera Ferrocarrilera (FOF) que aspiraba a cobijar a ese numeroso segmento de hombres de oficios, calificaciones, edades y nacionalidades variadas, en un gremio que lideraría junto a LF el conflicto más sobresaliente de la historia de los ferroviarios hasta ese entonces: la huelga general de 1917.

1. Este estudio resulta de una investigación doctoral en curso de F. D’Uva sobre los trabajadores y sindicatos ferroviarios en Argentina de la primera mitad del siglo XX, bajo la dirección de Valeria S. Pita, y de las investigaciones de S. Palermo sobre la protesta laboral y la protección social para las familias ferroviarias en dicho período. Ambas integran el Grupo de Historia Social y Género del IIEGE, UBA.

(Archivos, año IV, $\mathrm{n}^{\circ} 7$, septiembre de 2015, pp. 37-58) 
Este redoblamiento de la actividad gremial implicó mayores exigencias para las cúpulas sindicales. Conllevó un acercamiento entre LF y la FOF, a pesar de las diferencias ideológicas y organizativas que los distanciaban. De estructura centralizada y liderada por dirigentes de orientación socialista, LF se acercó a la FOF, tras las amargas lecciones aprendidas en la huelga de 1912, consciente de que sólo un movimiento de todos los trabajadores ferroviarios podía presionar con éxito a esas grandes y poderosas empresas. La FOF, por su parte, más joven y heterogénea, con una estructura descentralizada y una dirigencia ideológicamente más diversa, aunque predominara el sindicalismo, respondió positivamente y, en 1916, ambos gremios firmaron un pacto de solidaridad. En la huelga de 1917 actuaron conjuntamente, pero los resultados para ambos fueron disimiles. Maquinistas y foguistas obtuvieron gran parte de las demandas reclamadas y el gremio se consolidó. Por el contrario, algunos de los reclamos de los trabajadores de talleres, tráfico y vía y obras quedaron postergados y las disidencias internas condujeron al fin de la FOF. Su sucesora a partir de 1922, la Unión Ferroviaria se dotaría de una organización similar a la de LF.

Esta historia del sindicalismo ferroviario es bien conocida. Existen importantes estudios sobre su organización interna, sus orientaciones político-ideológicas, las luchas llevadas a cabo, su relación con el Estado y las empresas (Thompson, 1978; Goldberg, 1979; Gordillo, 1988; Suriano, 1991; Monserrat, 2011). Menos explorado, en cambio, ha sido el terreno de la vida sindical, de las actividades y prácticas cotidianas que acontecian en las numerosas seccionales de LF y la FOF, ubicadas a lo largo y ancho del país. Estas tenían una existencia regular, atenta a cuestiones que aquejaban a los trabajadores del lugar, y constituida sobre la base de vínculos forjados en el día a día, relaciones personales, afinidades y tensiones propias del compartir cotidiano. Al proponer explorar la vida sindical más que la organización gremial, este artículo abre una serie de interrogantes. ¿Qué vínculos cotidianos estructuraban y, a su turno, fortalecian la actividad gremial? ¿En qué prácticas se asentaban esos valores de compañerismo, solidaridad, organización y acción colectiva que sostenían los militantes y la prensa gremial?

Para ensayar una respuesta, examinaremos las características que adquirió la sociabilidad de los trabajadores ferroviarios sindicalizados en la Argentina de las primeras décadas del siglo XX. Al problematizar este aspecto de la vida sindical, esperamos brindar una comprensión más acabada sobre la identificación de los trabajadores con sus organizaciones obreras, el modo en que concebian sus oficios e, inclusive, la forma en que conceptualizaban sus derechos. Entendemos que esas prácticas propias de la vida gremial estaban informadas por concepciones sobre la diferencia sexual, que llevaban implícitas ciertas nociones 
de masculinidad y feminidad, que hablan de las obligaciones y también prerrogativas que los ferroviarios creían tener no sólo en tanto trabajadores sino en tanto varones, cuestiones distinguibles en el análisis pero inescindibles en la experiencia de los sujetos.

Nos interesa aquí, entonces, iluminar aspectos relacionados con las prácticas locales, cotidianas, en ocasiones más informales, que hacen a la sociabilidad de los ferroviarios. En tal sentido, retomamos una línea de indagación transitada por ciertas investigaciones del campo de la historia social, en particular de Argentina y otros países de América Latina, que han examinado la experiencia de los trabajadores no sólo en las instancias específicas de la explotación laboral sino también en el marco de sus redes familiares y comunitarias, sus asociaciones, tiempo libre, costumbres, vida cotidiana y relaciones de género (Klubock, 1992, 1998; Farnsworth-Alvear, 2000, Fontes, 2008; Lobato, 2000, 2001, 2011; Santos Souza, 2011). Mientras estos presupuestos han orientado varios estudios dedicados a la cultura de los trabajadores y su relación con las izquierdas (Barrancos 1990, 1992; Suriano 2001; Camarero 2007), estimamos que vale considerarlos a la hora de reflexionar sobre la vida gremial.

Indagar sociabilidades exige una referencia a los estudios pioneros de Maurice Agulhon para la Francia de mediados del siglo XIX, especialmente a aquellos dedicados a la clase obrera (Agulhon, 1992, 1994, 2009). Hace algunos años, Pilar González Bernaldo (2008) advirtió sobre el escaso impacto de su obra en la historiografia latinoamericana, la heterogeneidad implícita en el concepto de "sociabilidad" y la necesidad de reflexionar en torno a su utilidad como categoria para el análisis histórico. Aquí nos interesa estudiar los sindicatos ferroviarios desde una perspectiva innovadora, capaz de privilegiar la agencia de los trabajadores por sobre el examen de su estructura y organización institucional. Para ello, consideramos que las prácticas cotidianas y las formas de sociabilidad de las que participaban los ferroviarios agremiados constituyen un punto de mira privilegiado.

En suma, al poner el foco en las prácticas y discursos en torno a la sociabilidad, intentamos contribuir a la comprensión de aspectos poco conocidos de la vida gremial: la identidad de género de los ferroviarios organizados, su cultura obrera, sus instancias de formación, discusión y participación, y sus ideas sobre lo que implicaba integrar un gremio. Asimismo, nos interesa explorar hasta qué punto las familias de estos trabajadores formaron parte de esa sociabilidad gremial, o si por el contrario el sindicato actuó como un espacio de fraternidad predominantemente masculina. Al utilizar el concepto de género como categoría de análisis, buscamos recuperar la dimensión sexuada como constitutiva de la experiencia e identidad de los trabajadores organizados. 


\section{La materialidad de las seccionales}

Al recorrer las páginas de los periódicos de LF y la FOF se experimenta la sensación de estar viajando por gran parte del territorio argentino. Si bien las asambleas más importantes y el funcionamiento de los consejos y comisiones directivas centrales tenían lugar en la ciudad de Buenos Aires, el transcurrir de los gremios ferroviarios acontecía desperdigado en las muchas localidades donde se encontraban las seccionales, de muy diversas dimensiones. Algunas se destacaban por ser sede de núcleos relativamente abigarrados y estables de ferroviarios, tal es el caso de ciertas ciudades importantes como la Sección Bahía Blanca de la FOF que a fines de 1912 contaba con alrededor de quinientos asociados del Ferrocarril Pacífico y del Sud. ${ }^{2}$ Asimismo sobresalían por su peso numérico aquellas sedes de los grandes talleres de reparación del material ferroviario: Junín y Alianza en la provincia de Buenos Aires, Tafi Viejo en Tucumán, Rosario y Pérez en Santa Fe. Otras secciones contaban con un reducido número de socios, como señalaba $L F$ al referirse a ciertos galpones y depósitos "lejanos" como Necochea o Lamadrid. ${ }^{3}$ Más allá de sus dimensiones, lo cierto es que todas las seccionales publicitaban con ahínco sus actividades en las páginas de la prensa gremial.

Sin desestimar la relevancia de la voluntad, el activismo requería de disponibilidad de recursos materiales. Que un grupo de afiliados contara con una sede, un espacio fisico propio, no era un dato menor. Esto brindaba comodidad, cierta autonomía, grados de visibilidad y quizás de respetabilidad para nada desdeñables. Era un punto de encuentro para los trabajadores del lugar y también el ámbito que se ofrecía para los militantes de gira o para el paso de políticos ávidos de encontrar audiencias dispuestos a escucharlos. Pero una sede propia exigia dinero, energías y eventualmente solidaridad. De hecho, las actividades sindicales solian funcionar en lugares prestados o alquilados, práctica frecuente entre las organizaciones gremiales de la época. En uno de sus primeros números El Obrero Ferroviario (EOF) publicaba una noticia de Bahía Blanca, donde se había organizado una conferencia en el salón de la sociedad francesa "cedido gratuitamente para el acto". ${ }^{4}$ Salones de otras asociaciones, teatros o cines locales podían convertirse en sede ocasional de los eventos gremiales. Tal fue el caso de los festejos organizados por la sección fraternal de Tucumán en el $27^{\circ}$ aniversario de LF

2. "Bahía Blanca", El Obrero Ferroviario (EOF), n ${ }^{\circ}$, octubre 1912, año I, p. 4.

3. "De Lamadrid", La Fraternidad ( $L F)$, no 104, año VII, 1 de julio de 1914, p. 8; "Necochea", $L F, \mathrm{n}^{\circ}$ 128, año VIII, 1 de julio de 1915, p. 10.

4. "Bahía Blanca", EOF, n ${ }^{\circ}$ 5, año I, octubre de 1912, p. 4. 
en el Teatro Belgrano, cedido gratuitamente por las autoridades locales. ${ }^{5}$ Evidentemente habia que adecuarse a las comodidades disponibles, que en ciertos casos no eran muchas. Al inaugurar la sección Victoria del Ferrocarril Central Argentino, la FOF organizó una conferencia sobre la que comentó: "En breve es probable que se realice otra conferencia en un local más amplio" porque el utilizado había resultado "muy pequeño" ${ }^{6} \mathrm{~A}$ veces, las moradas de los trabajadores representaban el único lugar de reunión posible. Sobre la conferencia celebrada a mediados de 1915 por la sección de la FOF La Bajada, punto de intersección de varias líneas ferroviarias al sur de la provincia de Santa Fe, se informó que "el salón y el patio de la casa donde tenía lugar el acto, estaba completamente abarrotado de concurrentes". ${ }^{7}$

Por lo general, las carencias edilicias caracterizaban a aquellas seccionales pequeñas o con poco tiempo de vida, como lo eran muchas de las seccionales de la FOF. Inclusive, durante los primeros años de existencia de este gremio, sus encuentros solian tener lugar en las sedes que LF le cedia solidariamente. Este dato revela la disimil situación en la que se encontraban LF y la FOF entre 1912 y 1917. Para entonces, la primera contaba con veinticinco años de trayectoria, numerosas secciones a lo largo del país y un periódico mensual que comenzaría a publicarse de manera quincenal tras el reacomodamiento posterior a la huelga de principios de $1912 .{ }^{8}$ Por el contrario, la recién conformada FOF enfrentaba el desafio de reclutar socios y constituir secciones. No sólo se trataba de un gremio en creación sino que, dada su corta existencia y el hecho de que en general sus socios contaran con salarios inferiores a los de LF, estaba dotada de menores recursos. Resulta revelador, en tal sentido, que mientras en 1913 LF inició una campaña para adquirir su casa propia, la FOF, por esos años, aún recibía el apoyo de los fraternales para organizar sus encuentros. ${ }^{9}$

La necesidad de contar con recursos para financiar los gastos administrativos, el mantenimiento y la realización de ciertas actividades también daba cuenta de los requerimientos de la vida gremial. Así, las rifas para juntar fondos representaban una alternativa a la que echaron mano tanto la FOF como LF. Con alcances modestos, la primera organizó

\footnotetext{
5. "De Tucumán", $L F, \mathrm{n}^{\circ}$ 105, año VII, 15 de julio de 1914, p. 5.

6. "Victoria: una nueva sección", EOF, n 9, febrero de 1913, p. 4.

7. "La Bajada", EOF, n 31, junio de 1915, p. 4.

8. Para LF, la aparición quincenal de la revista era una aspiración que desde hacía tiempo manifestaba el gremio así como una prueba de su "potencialidad" y reorganización tras el conflicto de enero de 1912 ("Aparición quincenal de la Revista", $L F$, $\mathrm{n}^{\circ} 58,1$ de agosto de 1912, p. 7).

9. “Comunicado", EOF, no 4, año I, septiembre de 1912, p. 1.
} 
varias de ellas para sustentar la gira de los dirigentes más encumbrados por las distintas seccionales del país. A mediados de 1915, el comité organizador solicitaba que se le remitieran los importes recolectados y las boletas restantes para sortear una rifa, cuyos premios en orden de importancia eran: una biblioteca, la obra completa del anarquista Eliseo Reclus y un fonógrafo. ${ }^{10}$ En otras ocasiones, los objetivos de la recaudación eran muy puntuales, como cuando la seccional Alberdi puso en circulación una rifa con el fin de adquirir los útiles de la secretaria. ${ }^{11}$

Por su parte, la holgura relativa de LF no la eximia de las estrecheces propias de tiempos dificiles. Algunas secciones de LF organizaron rifas para costear la apertura y los materiales para bibliotecas y escuelas técnicas. ${ }^{12}$ La Comisión Directiva también apeló a una rifa para recaudar fondos para adquirir la casa propia, esfuerzo que se vio complicado por la coyuntura económica adversa. En efecto, a principios de 1916 debió postergar el sorteo hasta mayo de ese año, porque algunas secciones "han devuelto números no vendidos, por causas explicables y disculpables". ${ }^{13}$ Un espacio propio, reiteramos, era fundamental para desarrollar las actividades gremiales más elementales: afiliación de socios, realización de asambleas y celebración de conferencias de propaganda. Un local disponible posibilitaba el dialogo con los dirigentes gremiales en gira, ya fueran miembros de las comisiones directivas o militantes de otras organizaciones con las que los gremios sostenian vínculos, como la FORA, para el caso de la FOF, o el Partido Socialista, más cercano a LF. Estos intercambios solian ir acompañados por conferencias que reunían a los ferroviarios para ilustrarse en torno a las ventajas de la organización, el desarrollo del movimiento obrero y algunas cuestiones de especial interés, como la ley de jubilación ferroviaria.

Todas estas actividades brindaban la ocasión para que aquellos vínculos tejidos por los trabajadores en encuentros informales dentro y fuera del trabajo cristalizaran en una asociación con reglas fijas de funcionamiento. Asociadas a un espacio concreto y visible, estas prácticas y actividades fueron formalizándose y, al regularizar su frecuencia, contribuian a que hombres de distintas edades, nacionalidades y oficios gradualmente se sintieran hermanados por aquello que experimentaban les era común: su trabajo en empresas consideradas de vanguardia en materia tecnológica, símbolos de civilidad y modernidad; su pertenencia

10. "La rifa", $E O F, \mathrm{n}^{\circ} 32$, año IV, agosto de 1915, p. 4.

11. "Alberdi. Rifa en circulación”, EOF, n 44, año V, enero de 1917, p. 3.

12. "Las bibliotecas", $L F, \mathrm{n}^{\circ}$ 136, año IX, 15 de marzo de 1916, p. 8; "Alianza, F.C.B.", $L F, \mathrm{n}^{\circ} 167$ y 168 , año $\mathrm{X}, 1$ y 15 de agosto de 1917 , p. 5 .

13. "Rifa pro casa propia", $L F, \mathrm{n}^{\circ} 133$, año IX, 15 de diciembre de 1915, p. 6. 
al gremio de los fraternales o de ferrocarrileros y, en última instancia, su condición de obreros conscientes.

\section{La cotidianeidad de las seccionales}

Contar con una sede gremial era, sin duda, contar con un punto de encuentro. Una sede espaciosa posibilitaba organizar una biblioteca, un valor preciado para sindicatos que hacian de la difusión de la cultura letrada un baluarte indiscutible. Además, las bibliotecas brindaban espacio para el funcionamiento de escuelas populares nocturnas y cursos de formación, que satisfacian las demandas educativas de la comunidad. ${ }^{14}$ Varias noticias publicadas en los periódicos de ambos gremios asi lo documentan. En septiembre de 1916, LF invitaba a los socios y a sus hijos a concurrir al curso de dibujo lineal a dictarse en la biblioteca de Haedo. ${ }^{15}$ En agosto de 1916, en la inauguración de una biblioteca y sala de lectura de la seccional Santa Fe de la FOF, se anunció el dictado de clases de aritmética, geometría y gramática, tres dias a la semana. ${ }^{16}$

Inaugurar una biblioteca constituía un hecho tan preciado que ameritaba una celebración. LF solía realizar actos, en los que algunos oradores pronunciaban discursos alusivos al valor de la lectura y la elevación intelectual de los trabajadores. ${ }^{17}$ Numerosas noticias elogiaban la "buena obra" cumplida por las salas de lectura de las seccionales al poner al alcance de los trabajadores "libros que despierten su consciencia y aguzen (sic en el original) su inteligencia y lecciones que acrecienten sus conocimientos de la profesión". ${ }^{18}$ En la apertura de la biblioteca de la sección Tucumán, que alcanzaba por entonces cien asociados de los distintos departamentos del Ferrocarril Central Norte, se informó que la empresa, propiedad del estado nacional, la subvencionaría con cincuen-

14. Ver por ejemplo "Biblioteca Florentino Ameghino", $L F, \mathrm{n}^{\circ} 100$, año VII, 1 de mayo de 1914 , p. 7.

15. "Biblioteca Ferroviaria", $L F, n^{\circ} 145$, año IX, 1 de septiembre de 1916, p. 12. En el número siguiente se publicaba una fotografia de la biblioteca de la sección Santa Fe (F.C. Central Argentino), en la que se apreciaba al presidente y secretario de la misma y a un niño con un manojo de ejemplares de La Fraternidad en su mano ("La Biblioteca Obrera", $L F, \mathrm{n}^{\circ} 146$, año IX, 15 de septiembre de 1916, p. 8).

16. "Santa Fe", EOF, n ${ }^{\circ} 39$, año V, agosto de 1916, p. 3.

17. "Biblioteca en Ayacucho", LF, no 115, año VIII, 15 de diciembre de 1914, p. 8; "Educación y cultura. Biblioteca de Las Flores (S.)", $L F, \mathrm{n}^{\circ} 125$, año VIII, 15 de mayo de 1915, p. 5; "Inauguración de una biblioteca en Haedo (F.C.O.)", $L F, \mathrm{n}^{\circ} 129$, año VIII, 15 de agosto de 1915, p. 5.

18. "Movimiento cultural. Bibliotecas y Escuelas Técnicas. Una buena obra", $L F, \mathrm{n}^{\circ}$ 113, año VIII, 15 de noviembre de 1914, p. 5. 
ta pesos mensuales. ${ }^{19}$ Con frecuencia, se encomiaban las donaciones de diversas instituciones y autoridades, por ejemplo del Ministerio de Obras Públicas, por dotar a las bibliotecas de nuevas adquisiciones. ${ }^{20}$

Varios de los oficios ferroviarios representados por LF requerian de ciertos conocimientos para el ingreso y la promoción en la escala ocupacional, que el propio gremio se ocupó de transmitir. Así, junto a las bibliotecas solian funcionar las escuelas técnicas, que florecieron en casi todas las secciones fraternales en la década de $1910 .^{21}$ Estas perseguian diferentes fines: la instrucción de limpiamáquinas y de foguistas aspirantes a maquinistas, la capacitación del personal de conducción y, no menos importante, el fortalecimiento del "vínculo de compañerismo". ${ }^{22}$ Asimismo, figuraban entre sus objetivos "la enseñanza del idioma, hablado y escrito", "las nociones más esenciales de la aritmética y la geometría", y los temas de carácter estrictamente profesional. ${ }^{23}$ Preocupada por las carencias de las secciones más alejadas, LF tenía como máxima aspiración que existiera una escuela en cada sección. Por tanto, a principios de 1917 celebraba el incremento de los recursos en varias de sus escuelas y de su número de asistentes. Su funcionamiento era revelador del ideal de solidaridad compartido por sus integrantes: las clases solian dictarse de noche, por maquinistas "competentes" y "desinteresados", conscientes del valor de la instrucción para todo ferroviario que aspirase a aprobar las pruebas de idoneidad.

Los espacios educativos y culturales también servian como alternativas de otras actividades consideradas nocivas para el desarrollo de la organización, tales como el juego, la práctica de determinados deportes considerados "patronales" y el consumo de alcohol. Este último era considerado - por casi todas las organizaciones obreras de la época- el primer enemigo de los obreros conscientes y su erradicación la meta para lograr hogares más armoniosos y trabajadores más fuertes y sanos. ${ }^{24}$ Se instaba a los trabajadores "conscientes" a abandonar las tabernas, concurrir al local social y participar de las asambleas, uno de los deberes más elementales de todo buen afiliado. ${ }^{25}$ Del mismo modo,

19. "Las Bibliotecas", $L F, \mathrm{n}^{\circ}$ 149, año X, 1 de noviembre de 1916, p. 5.

20. "Biblioteca Obrera La Fraternidad", $L F, \mathrm{n}^{\circ} 139$, año IX, 1 de junio de 1916, p. 6; "La Biblioteca La Fraternidad", $L F, \mathrm{n}^{\circ}$ 150-153, año X, 1 de diciembre de 1916, p. 15.

21. "Escuela Técnica en Ingeniero White", $L F, \mathrm{n}^{\circ} 113$, año VIII, 15 de noviembre de 1914 , p. 5.

22. "Escuela Técnica", $L F, \mathrm{n}^{\circ} 75$, año VI, 15 de abril de 1913, p. 8.

23. "Varias", $L F, n^{\circ} 73$, año VI, 15 de marzo de 1913, p. 7.

24. "Contra el alcoholismo", $L F, n^{\circ} 73$, año VI, 15 de marzo de 1913, p. 3; "Por qué se quitó Juan de la bebida”, $L F, \mathrm{n}^{\circ} 100$, año VII, 1 de mayo de 1914, p. 5.

25. "De Bahía Blanca. Federación Obrera Ferrocarrilera", EOF, nº 6, año I, noviembre 
algunas notas advertian sobre los clubes atléticos manejados por ciertos superiores, que buscaban crear una "corriente de amistad y simpatia" entre jefes y personal, al tiempo que alejaban a los trabajadores de las asambleas y de la solidaridad gremial. ${ }^{26}$

Las bibliotecas, las escuelas técnicas, los cursos y escuelas nocturnas hacian que la vida en las seccionales desbordara los limites de las actividades gremiales propiamente dichas, restringidas a las cuestiones organizativas y de propaganda, para alcanzar a toda la comunidad. Lo que alli acontecía pasaba a incumbirle a un arco más amplio y diverso de personas y los motivos para relacionarse con las seccionales se diversificaban. Si para sostener la vida gremial, las relaciones personales y las afinidades locales contribuían tanto como la comunión ideológica y la propaganda de quienes estaban más comprometidos -militantes y lideres gremiales-, lo cierto es que el hecho de que las seccionales ofrecieran el "bienestar concreto del hogar colectivo", en palabras de M. Agulhon, hacía que éstas fortalecieran su presencia en la trama de la cotidianeidad, fruto de la acción de esos usos sociales tan diversos. ${ }^{27}$

Que la acción gremial se nutriera de esas relaciones personales y convirtiera en porosa la frontera entre la vida de las seccionales y la familiar lo prueba el hecho de que sus salones fueran utilizados para servicios fúnebres. Velar a los compañeros parecía una costumbre arraigada y practicada con asiduidad. Cuando un ferroviario fallecia, como en el caso del repentino deceso de Jesús Farías cumpliendo su labor en un galpón, el velatorio podía tener lugar en su domicilio. ${ }^{28}$ Esto no eximía, según ilustra el velatorio de Antonio González, que su ataúd pudiera llevarse primero al local social para luego ser velado en su casa. ${ }^{29}$ Las razones que sustentaban esta práctica pueden haber sido varias: las carencias materiales de las familias obreras que hacian

de 1912 , p. 3; "Las asambleas", $L F, \mathrm{n}^{\circ} 71-72$, año VI, 15 de febrero y 1 de marzo de 1913 , p. 3; "El viejo mal", $L F, n^{\circ} 80$, año VI, 1 de julio de 1913, p. 1; "Las asambleas seccionales", $L F, \mathrm{n}^{\circ} 153$, año X, 1 de enero de 1917, p. 3; "Los problemas de la organización", $L F, \mathrm{n}^{\circ} 163$, año $\mathrm{X}, 1$ de junio de 1917, p. 2.

26. "De Huinca Renancó", $L F, \mathrm{n}^{\circ} 102$, año VII, 1 de junio de 1914, p. 7; "De Justo Daract, F.C.P.”, $L F, n^{\circ} 147$, año X, 1 de octubre de 1916, p. 7. Sobre las prácticas deportivas promovidas por la empresa Ferrocarril Central Argentino, cf. Laura Badaloni (2010).

27. Al explicar el tránsito de la cofradía de oficio al sindicalismo profesional, pasando por el auge de los círculos en la Francia de 1830 y 1840, dicho autor señala que "éste es para esa época, la fórmula moderna que añade a los beneficios de la fraternidad el bienestar concreto del hogar colectivo que la asociación puede procurar y que el café daría menos cómoda y convenientemente" (1992), p. 161.

28. “Jesús Farias”, $L F, \mathrm{n}^{\circ}$ 136, año IX, 15 de marzo de 1916, p. 7.

29. "Antonio González", $L F, \mathrm{n}^{\circ} 161$, año X, 1 de mayo de 1917, pp. 7-8. 
que las seccionales se mostraran solidarias a la hora de ofrecer una despedida digna para el trabajador, o el hecho de que se tratara de individuos con una trayectoria reconocida en el sindicato y se buscara así honrar a los socios más antiguos y/o militantes más comprometidos. Igualmente importante era el hecho de que el fallecimiento hubiera ocurrido como resultado de un accidente trágico, una circunstancia por demás común y cuya publicidad dejaba a las claras los peligros del trabajo en el ferrocarril. Los accidentes, y más aún cuando provocaban víctimas fatales, suscitaban denuncias y reclamos, mediante los cuales las familias trabajadoras exponian sus concepciones sobre la protección social y la necesidad de contar con garantías y compensaciones que los protegieran de los eventuales infortunios que podian sufrir los ferroviarios en el cumplimiento de su trabajo. ${ }^{30}$

Cualquiera fuera el desencadenante de la muerte del trabajador, lo cierto es que los servicios fúnebres dejaban de pertenecer al terreno de lo privado y se convertían en rituales públicos, similares a los protagonizados por el anarquismo u otros gremios (Suriano, 2001; Lobato y Palermo, 2011). Una sucesión de eventos que se iniciaba en el velorio, generalmente en la sede social, y concluía en el cementerio, con los discursos de los dirigentes y compañeros más encumbrados o inclusive con la colocación de una placa o recordatorio en la tumba del fallecido. Estos rituales, brindaban una ocasión privilegiada para someter a juicio de la opinión pública la ética de las autoridades frente a estas circunstancias doloras, una evaluación de la que éstas usualmente no salían airosas.

Vale detenerse en algunos ejemplos. Tras el accidente fatal de Constantino Marino, militante de LF y trabajador del Ferrocarril Argentino del Norte, en abril de 1912, el velatorio tuvo lugar en el local social de la sección San Juan y concurrieron al entierro más de ciento cincuenta compañeros. ${ }^{31}$ Por su parte, los restos de Gelimer Agüero, fallecido tras una enfermedad, fueron velados en el local social de LF, en Tucumán, en donde varios compañeros pronunciaron discursos, por tratarse de un antiguo asociado de dicha sección. ${ }^{32} \mathrm{Al}$ enterarse de la muerte por enfermedad de Juan Figueroa, fraternal de la seccional Mechita y jefe de familia con cinco criaturas, la sección se reunió para honrar al compañero y adoptar medidas para asistir a la viuda y sus hijos. Se destacó la buena predisposición de la superioridad, que había arreglado los servicios para que el mayor número de compañeros pudiera asistir

30. "Necrológica", EOF, $\mathrm{n}^{\circ} 13$, año I, agosto de 1913, p. 2. Sobre las denuncias y reclamos de los ferroviarios y otros trabajadores en torno a los accidentes de trabajo, ver D’Uva, 2014 y 2015.

31. "Constantino Marino", EOF, n 20, año IV, mayo de 1914, p. 2.

32. "Gelimer Agüero", $L F, \mathrm{n}^{\circ} 126$, año VIII, 1 de junio de 1915, p. 8 
al sepelio. ${ }^{33}$ En otros casos, la vergonzosa actitud de las administraciones ferroviarias merecía una abierta condena. En Santos Lugares, por ejemplo, murió a causa de un accidente en julio de 1916 Juan Tuni, un compañero muy querido a punto tal que ochocientos obreros acompañaron sus restos al cementerio. Además de destacar este dato, la noticia denunció la "actitud odiosa, inhumana e incomprensible de los jefes y encargados del taller de Santos Lugares", quienes se negaron a dar franco al personal y ejercieron presión para minimizar tan importante acto. ${ }^{34}$

Pero por sobre todo, cualquiera fuera la actitud de las gerencias, lo que importaba resaltar era que la función protectora del gremio no tenía parangón ni competencia. Así lo dejaba trascender el relato sobre el sepelio de Luis Sartelli, un ferroviario de Haedo, fallecido a los dos dias de sufrir un accidente estando de servicio. El Ferrocarril Oeste, su empleador, facilitó un furgón de manera gratuita para el traslado de sus restos de Haedo a Flores y se hizo representar en el sepelio por varios jefes. Según informó $L F$, el acto en el cementerio fue imponente. Entre los oradores gremiales se destacó el redactor del periódico, Américo J. Baliño, quien aludiendo a la situación de los deudos, afirmó que LF "obrará en grande y noble misión, velando como madre tutelar sobre la gran familia". ${ }^{35}$ Seguramente para el auditorio, sus palabras no sonaban a retórica vacía, a la luz de las experiencias compartidas por los varones ferroviarios y sus familias en la cotidianeidad gremial. Su mensaje remitía a vivencias muy concretas, a redes de amistad, solidaridad, afinidades culturales no tan sólo ideológicas y a esa serie de prácticas compartidas en el día a día de la acción sindical.

En resumen, participar de la vida de los gremios ferroviarios aseguraba contar con un espacio físico de encuentro, un ámbito de pertenencia, donde se podía conocer a dirigentes y militantes de otros lugares, pasar un tiempo leyendo, haciendo un curso, asistiendo a una conferencia, sabiendo que en ese marco podia disfrutarse del valor del compañerismo, dignidad, respetabilidad y eventualmente de una asistencia solidaria para la propia familia en un trance de dificultad. ${ }^{36}$ No menos cierto, como se verá en la sección siguiente, ese marco brindaba oportunidades para la concientización gremial y política combinada con el esparcimiento.

33. “Juan Figueroa”, $L F, \mathrm{n}^{\circ}$ 129, año VIII, 15 de agosto de 1915, p. 6.

34. "Juan Tuni”, $L F, \mathrm{n}^{\circ} 144$, año IX, 15 de agosto de 1916, p. 8.

35. "Luis Sartelli", $L F, \mathrm{n}^{\circ} 118$ y 119, año VIII, 1 y 15 de febrero de 1915, p. 6.

36. Sobre el sindicato, la defensa del honor y la construcción de una fraternidad masculina, cf. Palermo (2009a). 


\section{Festejos ferroviarios: ¿una prerrogativa masculina?}

Aunque por definición los festejos son eventos extraordinarios, para los ferroviarios y sus familias, varias ocasiones eran buenas "para hacer un brindis". Como veremos, las celebraciones eran nutridas y diversas, parte constitutiva de las experiencias del mundo del trabajo y de las actividades promovidas por los propios gremios para la participación de sus afiliados y sus familias.

Algunos de estos festejos debían mucho a las propias características del trabajo ferroviario y puede que, de manera más general, a una sociedad de inmigración. Mientras las empresas ferroviarias ofrecian a sus trabajadores posibilidades de ascenso ocupacional, muchos de ellos por las características de su trabajo -en estaciones, como personal de tráfico o conductores de trenes- enfrentaban un traslado o, inclusive, varios. Para una comunidad abigarrada, con miembros que contaban con muchos años de antigüedad, también el retiro merecía celebrarse con quienes se había compartido tiempo, saberes del oficio, esfuerzos, sinsabores y alegrias. Estas eran fiestas de varones, momentos para la demostración del afecto generado en la cotidianeidad laboral, expresión acabada del valor que los hombres otorgaban no ya a la solidaridad de oficio ni de clase sino al compañerismo. De hecho, muchas de las noticias sobre esas despedidas se titulaban "fiestas del compañerismo". Así se presentaba el festejo de la partida a Inglaterra de un asociado de LF, que "fue siempre muy querido en la Sección Tolosa, con muchos amigos y de mucho corazón", por lo cual al conocerse su alejamiento se planeó despedirlo "dignamente". ${ }^{37}$ También se celebraba el regreso de los asociados, sobre todo el de aquellos con largas trayectorias, como el maquinista Alfredo Tanner, quien a fines de 1913 retornó de un viaje a Europa a la sección Burzaco. Allí, cincuenta compañeros le dieron una "cordial y entusiasta recepción" con un lunch y varios socios dirigieron la palabra, a quienes Tanner respondió "emocionadísimo". ${ }^{38}$ Las celebraciones se publicitaban en detalle si los homenajeados eran hombres comprometidos con la labor gremial. En estos casos, las noticias se titulaban "fiestas fraternales", como la celebrada por la sección de LF en Mar del Plata. El motivo de festejo era doble: la inauguración del escudo seccional y el obsequio a los compañeros J. Malvazzio y P. Bombelli por su laboriosa y acertada gestión sindical, la que dimitian para tomarse un "merecido descanso". ${ }^{39}$

37. "Una fiesta del compañerismo", $L F, \mathrm{n}^{\circ} 136$, año IX, 15 de marzo de 1916, p. 4.

38. "Una fiesta de fraternidad", $L F, \mathrm{n}^{\circ} 90$, año VII, 1 de diciembre de 1913, p. 3.

39. "Fiestas fraternales. En Mar del Plata (S.)", $L F, \mathrm{n}^{\circ} 131$, año VIII, 15 de octubre de 1915 , p. 7. 
Honrar al gremio suponía celebrar a sus militantes y también recordar sus luchas. La conmemoración de las huelgas, independientemente de sus resultados, servía para enfatizar el valor de la acción mancomunada (Palermo, 2009b). LF, por ejemplo, no cesó de conmemorar la huelga de enero de 1912. En su primer aniversario, todas las secciones realizaron asambleas de propaganda y solidaridad en las que se discutieron los pasos conducentes a la reorganización de las filas, lo que demostraba -según afirmaba el periódico- la firmeza de los ideales y la capacidad de reivindicación del gremio. ${ }^{40}$ En los años subsiguientes, varias secciones rememoraron la fecha con reuniones, brindis y picnics, de los que participaban todos aquellos que podian asistir, en especial quienes estaban de franco. ${ }^{41}$

Pero la fiesta gremial por excelencia era la celebración del aniversario de la fundación de estas organizaciones. LF la conmemoraba los días 20 de junio, mientras que la FOF lo hacía cada 5 de enero. Las características de estos festejos eran variadas. Una de las principales diferencias radicaba en el peso institucional (no sólo de recursos) de LF, fundada en 1887, frente a la recién nacida FOF. Hacia 1912, los festejos representaban una tradición para las seccionales de LF, en tanto que la FOF estaba iniciando esta práctica. En efecto, la información sobre su primer aniversario fue magra. En una breve reflexión, el periódico señaló que ese primer año había sido "el más dificil y penoso si se tienen en cuenta las dificultades del terreno a explorar." No obstante, prevalecía el optimismo pues se avizoraba que la FOF gradualmente se convertía en una organización "cuyos contornos bien dibujados pueden observarse en toda la extensión del país". ${ }^{42}$ Su segundo aniversario, en 1914, adquirió mayor nitidez. Se indicó que los festejos habian incluido acuñación de medallas, actos de propaganda y fiestas familiares. ${ }^{43}$ Para 1917, la FOF parecía haber alcanzado la madurez en términos de festejos de sus aniversarios. A raíz del pacto de solidaridad sellado entre ambos gremios unos meses antes, ese año muchas secciones festejaron conjuntamente.

Por supuesto, en el terreno de la sociabilidad cotidiana, asi como en el menos habitual de los festejos, las jerarquías del mundo laboral, las tensiones propias de las diferencias de edades u orígenes nacionales no desaparecían. Como es obvio, tampoco ese terreno permanecía

40. "El primer aniversario de las jornadas de enero-febrero 1912", LF, n ${ }^{\circ} 69-70$, año VI, 1 de febrero de 1913, p. 6.

41. "Fiestas fraternales", $L F, \mathrm{n}^{\circ}$ 93, año VII, 15 de enero de 1914, p. 5; "6 de Enero de 1912. 3er Aniversario", $L F, \mathrm{n}^{\circ} 116$, año VIII, 1 de enero de 1915, p. 4; "De Libertad", $L F, \mathrm{n}^{\circ} 135$, año IX, 15 de febrero de 1916, p. 6.

42. "Reflexiones", EOF, n 9, año I, febrero de 1913, p. 2.

43. "Nuestro segundo aniversario", EOF, $\mathrm{n}^{\circ} 17$, año II, febrero de 1914, p. 1. 
indemne a las disputas ideológicas en las que se involucraban no sólo los militantes sino todos los trabajadores ferroviarios. Pero el desafio interpretativo de la historia social de los trabajadores no consiste tan sólo en dilucidar los motivos que los distancian, sino que exige además explicar cómo se construyen lazos, vínculos -ideológicos pero también culturales y afectivos- que sustentan la creación de un colectivo con una identidad común. Esto último persigue este artículo al ahondar en la sociabilidad gremial. En primer lugar, por tanto, vale subrayar aquí que fue precisamente en ese terreno de costumbres compartidas, en la distensión de un festejo -como también en el compartir la biblioteca, las clases nocturnas, o inclusive un sepelio- que esas diferencias, sin necesariamente diluirse, podian ponerse entre paréntesis. En un festejo conjunto de dos gremios por entonces aliados, un trabajador de via y obras y un maquinista podian convivir, un nativo y un extranjero podian intentar comunicarse, un anarquista o sindicalista podían llegar a tolerar, seguramente a desgano, la perorata de un invitado socialista, o viceversa. Lo que hacia posible que personas tan diversas compartieran un festejo era la afinidad nacida del compartir la experiencia de explotación, la conciencia de vivenciar diariamente que su suerte se ataba a la fortaleza de vínculos solidarios y no a la aventura individual. Quizás por esa razón hombres tan diversos podian disfrutar de un festejo, sin mayor exigencia de homogeneidad y, en tanto tales, celebrar su condición de ferroviarios agremiados.

En segundo lugar, explorar la sociabilidad de los ferroviarios y, en particular, los festejos, nos permite traer a la luz los sentidos y las tensiones que el ejercicio de la masculinidad acarreaba en la práctica. Priorizamos aquí las disrupciones que se hacen visibles al tomar en cuenta la dimensión sexuada de la experiencia de los trabajadores. ¿La celebración del aniversario gremial era una ocasión para que sólo los varones festejaran y discurrieran sobre la organización obrera o era, en cambio, un evento familiar, dedicado a la reflexión, el entretenimiento, o a ambos a la vez? Esta cuestión suponía una concepción de lo público y lo privado que, como recuerda la teoría feminista, está estructurada por la diferencia de género. Los festejos, como esperan demostrar los casos analizados debajo, documentan la participación pública no ya de los trabajadores varones sino de sus familiares mujeres, e inclusive de sus hijos e hijas. Y, debe notarse, estas prácticas ponian en tensión la prerrogativa masculina de su predominio en la esfera pública, en tanto el papel de ciudadano, productor y proveedor correspondian al varón, mientras que la domesticidad se asociaba inexorablemente a la feminidad.

Por ejemplo, en 1917, el festejo por el aniversario de la FOF, realizado en el local fraternal de Ayacucho, contó con numerosos afiliados de 
ambos gremios, acompañados de sus familias. La cena de fiesta incluyó la lectura de discursos, la palabra del secretario del centro socialista local y dejó tiempo para el esparcimiento familiar pues "hubo banda de música y una orquesta improvisada por grupo de obreros socios del centro recreativo "la lira de oro"". ${ }^{44}$ De igual manera, en el festejo de Ing. White, realizado en un salón por la noche, se entonaron el himno "Hijos del Pueblo", "La Internacional", una niña recitó una poesía titulada "La Obrera" y se presentaron cuadros dramáticos. Dirigió la palabra el diputado socialista Domingo Bessaso y un compañero de LF, quien apeló a la mujer "a quien pidió que fuera la mayor cooperadora del obrero en las luchas de reivindicación social". Todo terminó con un animado baile, que se prolongó hasta la madrugada. ${ }^{45}$ Por su parte, la celebración de la sección Talleres del Ferrocarril Sud en 1915 también comprendió diferentes momentos. Consistió en una conferencia con oradores invitados, entre ellos el diputado socialista Francisco Cúneo, y hacia la noche tuvo lugar una fiesta familiar con buffet en la que invitados especiales pronunciaron discursos, una niña recitó poesía, se representaron cuadros dramáticos y se bailó hasta la madrugada. ${ }^{46}$

En las grandes ciudades, capitales de provincia, y en aquellas localidades importantes, sede de grandes talleres de reparación, el festejo se integraba y a la vez expresaba la modernidad del paisaje urbano. Las celebraciones se desarrollaban en los locales sociales o en algún salón especialmente reservado para la ocasión como teatros, cines, hoteles o restaurantes. Incluian varios divertimentos para las familias: juegos, rifas y repartos de juguetes. Tocaban orquestas, algunas formadas por los mismos ferroviarios, se representaban cuadros dramáticos y se proyectaban cintas en cinematógrafos. Usualmente, estas actividades se combinaban entre sí, como lo hizo en 1913 la sección de LF en Corral de Bustos, al organizar una conferencia en el local social, un almuerzo criollo en la casa de un compañero, juegos atléticos y un baile familiar. ${ }^{47}$

Ciertamente, los aniversarios de los gremios constituian un momento de especial solidaridad, una instancia propicia para el encuentro, en el que los trabajadores y sus familias reforzaban los vínculos de solidaridad y camaradería mediante la realización de actividades que incluian a hombres y mujeres de distintas edades, contribuyendo a redefinir los contornos de la familia ferroviaria. ${ }^{48}$ Como se ha visto, mujeres y

44. EOF, febrero de 1917 , p. 2 y "Las fiestas gremiales", $L F, \mathrm{n}^{\circ} 155$, año X, 1 de febrero de 1917, p. 8.

45. "De Ingeniero White, F.C.S.", $L F, \mathrm{n}^{\circ} 155$, año X, 1 de febrero de 1917, p. 8.

46. "Los Talleres", $L F, \mathrm{n}^{\circ} 128$, año VIII, 1 de julio de 1915, p. 7.

47. "De Corral de Bustos", $L F, \mathrm{n}^{\circ} 81$, año VI, 15 de julio de 1913, p. 5.

48. Sobre la redefinición de la familia ferroviaria en contextos de protesta, los ideales 
niños participaban activamente llevando a cabo tareas específicas que contribuian al éxito de las jornadas. Siguiendo la tradición de proselitismo infantil propia de las vanguardias obreras que ha señalado Dora Barrancos (1987), hijos e hijas de los compañeros recitaban poesias, entonaban canciones y/o representaban cuadros dramáticos y monólogos. A su vez, las mujeres se encargaban de variadas tareas, como la decoración de los locales para la ocasión, participación que solía destacarse en las crónicas de los festejos. Asimismo, en varias oportunidades se subrayó la directa apelación que se le hacía a las mujeres como cuando en 1915 el secretario de la sección Junín de LF exhortó a las madres, esposas, hermanas e hijas de los compañeros a aportar su "valioso concurso moral" a la obra de la organización. ${ }^{49}$ Más importante aún, algunas mujeres encontraron en estos festejos una oportunidad para ejercer sin reparos sus libertades públicas, y en algunas ocasiones tomaron la palabra, como sucedió en la sección fraternal de Mechita en 1916. En ese festejo participaron más de ciento cincuenta personas, entre ellas cuarenta y cinco mujeres y cuarenta niños. Al momento de los discursos, una señorita hizo uso de la palabra. ${ }^{50}$ Ese mismo año, la sección Talleres de LF invitó a la celebración a la militante socialista Juana María Begino, quien dedicó parte de su disertación a demostrar "especialmente a la enorme concurrencia femenina" las falsedades de la religión. Asimismo aconsejó a las mujeres dedicarse a actividades como la educación de sus hijos, "para que también ellos luchen mañana por la causa de nuestra emancipación". ${ }^{51}$

Como se ha visto, en ocasión de los festejos, la vida sindical favorecía una oportunidad de sociabilidad para hombres, mujeres, niñas y niños. Y si bien esos eventos contribuian a exaltar la figura del trabajador agremiado y el valor de la organización, no coadyuvaban a conceptualizar lo público y la política como esferas exclusivamente masculinas. Al menos en la década de 1910, por razones complejas que es imposible desbrozar en el marco de este artículo, ciertas prácticas de aquellas organizaciones gremiales integradas principalmente por hombres daban espacio no ya a la diversión sino a la politización de las familias obreras, en especial de las mujeres trabajadoras.

Quizás la prerrogativa masculina que los sindicatos ferroviarios defendian sin fisuras y que hacía al poder del trabajador varón era el derecho y el deber de mantener su hogar. Desde la óptica gremial,

de masculinidad y feminidad puestos en juego en el conflicto y los debates en torno a la respetabilidad de las familias obreras, ver Palermo (2013).

49. “Junín”, $L F, \mathrm{n}^{\circ} 128$, año VIII, 1 de julio de 1915, p. 11.

50. "Mechita", $L F, \mathrm{n}^{\circ} 141$, año IX, 1 de julio de 1916, p. 4.

51. "Talleres", $L F, \mathrm{n}^{\circ} 141$, año IX, 1 de julio de 1916, p. 4. 
el trabajador ferroviario debía ser responsable de su familia, esto es, ser un varón proveedor. Por supuesto que, en la práctica, las magras remuneraciones de la mayoría de los ferroviarios exigian que los otros miembros del hogar trabajaran para poder afrontar el presupuesto familiar. Pero en la teoría, este principio era firmemente sostenido por los gremios y no se ponía en duda. Al respecto, resulta reveladora la celebración realizada en Ceres a propósito del aniversario de LF en 1914. El festejo tuvo lugar en la casa especialmente construida por los compañeros de esa y otras secciones del Central Argentino para la viuda y los seis hijos del maquinista Lorenzo Soto, fallecido pocos meses antes. ${ }^{52}$ Esta casa representaba a la perfección el ideal de solidaridad y fraternidad esgrimido por el gremio, del que se esperaba incluso que protegiera a la familia en los casos en que el trabajador ya no podía garantizar el bienestar de los suyos. Desaparecido el varón proveedor, el gremio había tomado su lugar, ocupándose del porvenir de los deudos que continuaban en una relación estrecha con quienes fueran los compañeros del extinto jefe de familia.

En síntesis, teñidos por la algarabía u opacados por la cercanía de pérdidas irreparables, los aniversarios gremiales nunca dejaban de celebrarse. El compañerismo, la solidaridad, la consciencia, la educación societaria y el respeto por la profesión eran algunos de los valores que se exaltaban durante estas fechas. Y fuera en un clima distendido o de congoja, el mensaje que trasuntaban esas prácticas (y no simplemente los discursos asociados a los festejos) era el mismo: estos gremios simbolizaban la unión de hombres de oficio, de obreros conscientes, de varones dignos capaces de cumplir incondicionalmente con el mandato de su género: ser buenos padres de familia y referentes confiables en sus comunidades.

\section{Palabras finales}

En este artículo hemos optado por privilegiar una dimensión analítica que siguiendo a M. Agulhon puede denominarse "cultural, a falta de un adjetivo más apropiado," en palabras del autor. Hace ya tiempo, en uno de sus escritos señalaba:

Nuestra posición es que la conciencia y la organización del mundo del trabajo no son solamente tributarios de lo que ocurre en la esfera económica y en la esfera politica, sino un poco también de la evolución de las costumbres: costumbres

52. "De Ceres", $L F, \mathrm{n}^{\circ}$ 106, año VII, 1 de agosto de 1914, p. 5. 
de los mismos obreros, o costumbres de los burgueses y pequeñoburgueses. (Agulhon, 1999: 166)

Años antes aclaraba también "hemos querido señalar aquí una línea de investigación y de reflexión, sin estar seguros de que sea la más importante; nuestra única certeza es que no se debería negligir aún cuando sea considerada como menor" (Agulhon, 1992: 165).

Esta pesquisa ha buceado en esta dirección. Absorbidos por un trabajo demandante, muchas veces riesgoso, pero a la vez imbuido del prestigio que otorgaba el ferrocarril como simbolo de modernidad, esos varones trabajadores encontraban en la pertenencia a sus gremios motivos para enorgullecerse y, podriamos decir, una fuente de respetabilidad. Como hemos visto, esos sindicatos ferroviarios se nutrian de una vida seccional relativamente activa, sustentada en vínculos personales, en prácticas cotidianas que, en muchos casos, involucraban no sólo a los ferroviarios sino también a sus familias. Por supuesto, la acción gremial suponía afiliarse, asistir y tomar decisiones en las asambleas y congresos, debatir estrategias de organización y de lucha. Pero implicaba también otras actividades, sobre las que hemos insistido aquí, que no pueden desestimarse. Ellas eran fundamentales, como señalara acertadamente J. Horowitz (1985), para crear una identificación con el gremio y fomentar el sentido de pertenencia a una elite obrera. Contribuyen a explicar la fortaleza de esa acción gremial, construida a partir de vínculos de camaradería masculina, afectos y tiempos compartidos, confianza en que las seccionales cobijaban el estudio, el acompañamiento en tiempos de dolor, el espacio para la discusión gremial y política pero también para la recreación. Hemos demostrado que esas prácticas no eran neutrales en términos de género, sino que revelaban prescripciones bien definidas sobre la masculinidad. Esto es, la dignidad del trabajador se manifestaba y reforzaba en la identificación con un trabajo prestigioso, con oficios calificados y modernos; en la pertenencia a gremios fuertes y solidarios pero también en el desempeño del papel de protector de su familia, del garante de su bienestar. Así, la reconstrucción de la sociabilidad de los ferroviarios agremiados ilumina sobre aspectos menos indagados de la vida sindical, ofreciendo pistas para explicar su arraigo y fortaleza, para comprender el modo que las seccionales adquirieron presencia y devinieron en referentes en sus diferentes localidades.

Para explorar estas cuestiones hemos dependido de la prensa gremial que, como se ha visto, provee información generosa sobre las seccionales. Sin embargo, es imposible desconocer sus sesgos. Las noticias allí publicadas reflejan sólo la vida de un grupo limitado de ferroviarios, aquellos más involucrados en la cotidianeidad sindical. Sus relatos tienden a traducir una visión idílica, ejemplificadora de la 
acción gremial y de aquellos que la practicaban. Pero bien miradas, las páginas de estos periódicos también sugieren indicios sobre la distancia que mediaba entre los ideales y las experiencias vividas, las tensiones que afloraban en las brechas existentes entre ciertas costumbres y las demandas de la militancia.

Hace ya varias décadas que buena parte de la renovación en la historia social de los trabajadores se debe a las contribuciones de la historia de las mujeres obreras. Esta historiografia ha puesto en primer plano el modo en que el cumplimiento de las prescripciones genéricas respecto a la feminidad, en especial el ideal de domesticidad, afectó la agencia de las mujeres en su participación en el trabajo, las organizaciones obreras y la protesta así como sus concepciones de derechos en tanto trabajadoras, lo cual era inseparable de su condición de mujeres. Aquí se ha tratado de avanzar en la misma dirección para poner de relevancia que el recuperar la dimensión genérica de la experiencia de clase de trabajadores varones puede contribuir en mucho a comprender sus modos de vivir y pensar sus actividades gremiales, y el lugar y la función que en la vida de ellos mismos y de sus familias desempeñaban esas organizaciones obreras. En teoria, a nivel discursivo, un ferroviario consciente, activo en el gremio era, en tanto tal, un buen padre de familia, o al menos podía llegar a serlo. Según la prédica de los periódicos gremiales, su participación en la organización le permitía legar a sus descendientes la mejor herencia: el valor de la solidaridad. Pero lo que se conciliaba en el discurso no siempre se traducía a la práctica y esa convergencia entre un buen agremiado y un buen padre de familia no siempre resultaba necesaria, ni posible. Puede que un buen ferroviario, esforzado, anhelara pasar sus horas libres descansando o haciendo algunos arreglos hogareños, de los que solian ocuparse los varones de la casa. Podría pensarse que existía también, a riesgo de exagerar, una "domesticidad masculina", dominguera, de días no laborales. Así lo deja entrever una noticia publicada por $L F$ en 1916, que llamaba la atención a los "semi-socios" que se excusaban de asistir a las reuniones alegando que estaban enfermos, o que tenían enfermos en su casa o que debian "arreglar las patas de la silla" ${ }^{53}$ Esas eran maneras de ejercer una paternidad responsable, hábitos que hablaban del ejercicio de una masculinidad digna y respetable por parte de los ferroviarios pero que no se conciliaban con las prácticas que se asociaban al comportamiento de un obrero consciente, de un buen agremiado de LF o de la FOF. Y si bien se predicaba que la pertenencia al gremio contribuía a hacer de los ferroviarios hombres respetables, buenos padres de familia, lo cierto es que ambas cosas podian entrar en tensión. En consecuencia,

53. "De Justo Daract, F.C.P.”, $L F, \mathrm{n}^{\circ}$ 147, año X, 1 de octubre de 1916, p. 7. 
más allá de las ventajas que por entonces suponía el ser varón, y de los modos en que los gremios mediante sus discursos y prácticas reforzaban dichas prerrogativas, los ferroviarios pudieron, en ocasiones, haberse enfrentado al dilema al que los exponía el cumplimiento simultáneo de las prescripciones del género y del ideal gremial.

\section{Bibliografia}

Agulhon, Maurice (1992), "Clase obrera y sociabilidad antes de 1848", Historia Social, $\mathrm{n}^{\circ} 12$, invierno, pp. 141-166.

- (1994), Historia vagabunda. Etnología y politica en la Francia contemporánea, México: Instituto Mora.

- (2009), El círculo burgués. La sociabilidad en Francia, 1810-1848 [1977], Buenos Aires: Siglo XXI.

Badaloni, Laura (2010), "La familia ferroviaria a principios del siglo XX: bienestar y lealtades de hierro en el Ferrocarril Central Argentino", en Daniel Dicósimo y Silvia Simonassi (comps.), Trabajadores y empresarios en la Argentina del siglo XX: indagaciones desde la historia social, Rosario: Prohistoria.

Barrancos, Dora (1987), "Los niños proselitistas de las vanguardias obreras", Documentos de Trabajo, $\mathrm{n}^{\circ}$ 24, Buenos Aires: CEIL.

- (1990), Cultura, educación y trabajadores, 1890-1930, Buenos Aires: CEAL.

- (1992), Anarquismo, educación y costumbres en la Argentina de principios de siglo, Buenos Aires: Contrapunto.

Camarero, Hernán (2007), A la conquista de la clase obrera. Los comunistas y el mundo del trabajo en la Argentina, 1920-1935, Buenos Aires: Siglo XXI.

D’Uva, Florencia (2014), "En reclamo de un resarcimiento: trabajadores y accidentes de trabajo en Buenos Aires (1900-1915)", Páginas, Rosario, año $6, \mathrm{n}^{\circ} 12$, pp. $7-26$.

- (2015), "Los trabajadores ferroviarios y los accidentes de trabajo. Argentina, 1907-1915", Actas de las V Jornadas Nacionales de Historia Social, La Falda, Córdoba.

Farnsworth-Alvear, Ann (2000), Dulcinea in the Factory: Myths, Morals, Men and Women in Colombia's Industrial Experiment, 1905-1960, Durham, Duke University Press.

Fontes, Paulo (2008), Um Nordeste em São Paulo. Trabalhadores migrantes em São Miguel Paulista (1945-1966), Río de Janeiro: Editora FGV.

Goldberg, Heidi (1979), "Railroad Unionization in Argentina, 1912-1929. The Limitations of a Working class Alliance", Yale University.

González Bernaldo, Pilar (2008), "La "sociabilidad" y la historia política", Nuevo Mundo Mundos Nuevos [en línea], Biblioteca de Autores del Centro, puesto en línea el 17 febrero 2008.

Gordillo, Mónica (1988), El movimiento obrero ferroviario desde el interior del país (1916-1922), Buenos Aires: CEAL. 
Horowitz, Joel (1985), "Los trabajadores ferroviarios en la Argentina (19201943). La formación de una elite obrera", Desarrollo Económico, vol. 25, $\mathrm{n}^{\circ}$ 99, octubre-diciembre.

Iñigo Carrera, Nicolás (2013), “Aproximación al análisis del Centenario como hito en la historia de la confrontación social argentina", PIMSA. Documentos y comunicaciones, 2011-2012, n²14, edición digital, pp. 69-116.

Klubock, Thomas (1992), "Sexualidad y proletarización en las minas de E1 Teniente", Proposiciones, $\mathrm{n}^{\circ} 21$.

- (1998), Contested Communities. Class, Gender, and Politics in Chile's El Teniente Copper Mine, 1904-1951, Duke University Press.

Lobato, Mirta Zaida (2000), "Los trabajadores en la era del "progreso"", en Mirta Lobato (dir.), Nueva historia argentina, tomo V, Buenos Aires: Sudamericana.

- (2001), La vida en las fábricas. Trabajo, protesta y politica en una comunidad obrera, Berisso (1904-1970), Buenos Aires: Prometeo.

- (2009), La prensa obrera, Buenos Aires: Edhasa.

- y Silvana Palermo (2011), "Del trabajo a las calles: dignidad, respeto y derechos para los y las trabajadoras", en Mirta Lobato (ed.), Manifestaciones, fiestas y rituales en el siglo XX, Buenos Aires: Biblos.

Monserrat, Maria Alejandra (2011), "Los trabajadores ferroviarios: sus luchas y organizaciones sindicales en el contexto de la Argentina gobernada por el radicalismo (1916-1930)", en Cuadernos del Ciesal, año 8, n 10, Rosario, pp. 97-118.

Palermo, Silvana (2007), “¿Trabajo masculino, protesta femenina? La participación de la mujer en la gran huelga ferroviaria de 1917", en María Celia Bravo, Fernanda Gil Lozano y Valeria Pita (comps.), Historias de luchas, resistencias y representaciones. Mujeres en la Argentina, siglos $X I X$ y XX, Editorial de la Universidad Nacional de Tucumán.

- (2009a), "Masculinidad, conflictos y solidaridades en el mundo del trabajo ferroviario en Argentina (1912-1917)", Revista Mundos do Trabalho. Publicação Eletronica Semestral do GT Mundos do Trabalho, vol. 1, no 2, julio-diciembre, pp. 94-123.

- (2009b), "Fiestas y celebraciones públicas desde una perspectiva histórica: los festejos tras la gran huelga ferroviaria de 1917", en AA.VV., Lo celebratorio y lo festivo: 1810/1910/2010. La construcción de la nación a través de lo ritual, Buenos Aires: Comisión para la Preservación del Patrimonio Histórico Cultural de la Ciudad de Buenos Aires.

- (2013), "En nombre del hogar proletario: Engendering the 1917 Great Railroad Strike in Argentina", Hispanic American Historical Review, vol. 93, $\mathrm{n}^{\circ} 4$, noviembre, pp. 585-620.

Santos Souza, Robério (2011), “Tudo pelo trabalho libre!", Trabalhadores e conflitos no pós-abolição (Bahia, 1892-1909), Salvador: EDUFBA-FAPESP.

Suriano, Juan (1991), "Estado y conflicto social: el caso de la huelga de maquinistas ferroviarios de 1912", en Boletín del Instituto de Historia Argentina y Americana, Dr. E. Ravignani, ${ }^{\circ} 4,2^{\circ}$ semestre, pp. 91-115. 
- (2001), Anarquistas, cultura y politica libertaria en Buenos Aires, 18801910, Buenos Aires: Manantial.

Thompson, Ruth (1978), "Organized Labor in Argentina: The Railway Unions to 1922", tesis doctoral, Oxford University.

$* * *$

Titulo: Masculine union life and sociability: the railroad workers in Argentina in the early twentieth century

Resumen: Este artículo analiza la sociabilidad de los trabajadores, tomando como casos de estudio dos gremios ferroviarios: La Fraternidad, compuesta por maquinistas y foguistas, y la Federación Obrera Ferrocarrilera, integrada por trabajadores de tráfico, talleres y vía y obras. Explora qué actividades realizaban los trabajadores en sus seccionales -más allá de aquellas propias del funcionamiento interno del gremio- y quiénes participaban en ellas. Para ello examina los periódicos La Fraternidad y El Obrero Ferroviario entre 1912 y 1917, un quinquenio enmarcado por la primera huelga general de maquinistas y la primera huelga general respectivamente. Centrado en las sociabilidades más que en las representaciones, persigue arrojar luz sobre la vida sindical privilegiando el examen de la agencia de los trabajadores por sobre el de la organización institucional y, al tomar el concepto de género como categoría de análisis, recupera la dimensión sexuada como constitutiva de la experiencia de los trabajadores.

Palabras clave: ferroviarios - sociabilidad - género - sindicalismo

Abstract: This article analyzes the sociability of the working class, taking as case studies two railroad trade unions: La Fraternidad, made up of enginemen and firemen and the Federación Obrera Ferrocarrilera, comprised by traffic personnel, shop men and track laborers. It explores the activities that workers engaged into in their local unions -beyond those strictly related to the internal organization- and who participated in them. To do so, this study is based on the information provided by the union journals, La Fraternidad and El Obrero Ferroviario, between 1912 and 1917, a five year period encompassed by the first general strike of the enginemen and the first national strike. It concentrates on workers' sociability more than cultural representations. By examining workers' agency instead of trade unions' institutional organization, and taking gender as a useful category of analysis, this article seeks to shed light on trade union life and highlight the sexual dimension of workers' experiences.

Keywords: railroad workers - sociability - gender - labor unions

Recepción: 6 de mayo de 2015. Aprobación: 25 de julio de 2015 . 